\title{
Dichotomy between the humoral and cellular responses elicited by mRNA and adenoviral vector vaccines against SARS- CoV-2
}

Rahul Ukey ${ }^{1 \dagger}$, Natalie Bruiners ${ }^{1,2+}$, Hridesh Mishra ${ }^{1 \dagger}$, Pankaj K. Mishra ${ }^{1 \dagger}$, Deborah McCloskey $^{3}$, Alberta Onyuka $^{4}$, Fei Chen ${ }^{3}$, Abraham Pinter ${ }^{1,2}$, Daniela Weiskopf ${ }^{5}$, Alessandro Sette ${ }^{5,6}$, Jason Roy ${ }^{7}$, Sunanda Gaur ${ }^{8}$ and Maria Laura Gennaro ${ }^{1,2^{*}}$

\begin{abstract}
Background: Protection from severe disease and hospitalization by SARS-CoV-2 vaccination has been amply demonstrated by real-world data. However, the rapidly evolving pandemic raises new concerns. One pertains efficacy of adenoviral vector-based vaccines, particularly the single-dose Ad26.COV2.S, relative to mRNA vaccines.

Main body: We investigated the immunogenicity of Ad26.COV2.S and mRNA vaccines in 33 subjects vaccinated with either vaccine class 5 months earlier on average. After controlling for the time since vaccination, Spike-binding antibody and neutralizing antibody levels were higher in the mRNA-vaccinated subjects, while no significant differences in antigen-specific B cell and T cell responses were observed between the two groups.

Conclusions: A dichotomy exists between the humoral and cellular responses elicited by the two vaccine classes. Testing only for humoral responses to compare the durability of SARS-CoV-2 vaccine-induced responses, as typically performed for public health and research purposes, is insufficient.
\end{abstract}

Keywords: Ad26.COV2.S, BNT162b2, mRNA-1273, Antibody binding, Neutralizing antibodies, Antigen-specific B cells, Antigen-specific T cells

\footnotetext{
* Correspondence: gennarma@njms.rutgers.edu

${ }^{\dagger}$ Rahul Ukey, Natalie Bruiners, Hridesh Mishra and Pankaj K. Mishra contributed equally to this work.

${ }^{1}$ Public Health Research Institute, Rutgers New Jersey Medical School, ICPH Building, W250Q, 225 Warren Street, Newark, NJ 07103, USA

${ }^{2}$ Department of Medicine, Rutgers New Jersey Medical School, ICPH building, W250Q, 225 Warren Street, Newark, NJ 07103, USA

Full list of author information is available at the end of the article
}

(C) The Author(s). 2022 Open Access This article is licensed under a Creative Commons Attribution 4.0 International License, which permits use, sharing, adaptation, distribution and reproduction in any medium or format, as long as you give appropriate credit to the original author(s) and the source, provide a link to the Creative Commons licence, and indicate if changes were made. The images or other third party material in this article are included in the article's Creative Commons licence, unless indicated otherwise in a credit line to the material. If material is not included in the article's Creative Commons licence and your intended use is not permitted by statutory regulation or exceeds the permitted use, you will need to obtain permission directly from the copyright holder. To view a copy of this licence, visit http://creativecommons.org/licenses/by/4.0/ The Creative Commons Public Domain Dedication waiver (http://creativecommons.org/publicdomain/zero/1.0/) applies to the data made available in this article, unless otherwise stated in a credit line to the data. 
With the COVID-19 pandemic still raging and new SARS-CoV-2 variants, such as Delta (B.1.617.2), exhibiting increased transmissibility [1], concerns have been raised about the efficacy of current vaccines in general as well as relative to each other. The SARS-CoV-2 vaccines that have received full approval or emergency use authorization by the US Food and Drug administration include the mRNA vaccines BNT162b2 (BioNTech-Pfizer) [2] and mRNA-1273 (Moderna) [3], which are administered in two doses, and the single-dose, adenoviral vector vaccine Ad26.COV2.S (Johnson and JohnsonJanssen) [4]. Comparisons of protective immune responses elicited by these vaccines have focused on neutralizing titers in the plasma [for example, $[5,6]]$. Virus neutralization by plasma is critical to protect against viral infection, but understanding the efficacy and durability of vaccine-induced responses requires assessing both humoral and cellular adaptive immune responses elicited by vaccination.

Here, we used quantitative assays to compare antibody binding and neutralizing titers, antigen-specific $\mathrm{B}$ cell frequencies, and antigen-specific $\mathrm{T}$ cell responses in thirty-three participants with no history of SARS-CoV-2 infection, similarly divided between subjects fully vaccinated with mRNA vaccines $(n=16)$ or the adenoviral vector vaccine $(n=17)$. When we compared the two groups by age, gender, and co-morbidities, we found no difference in these variables except for the time elapsed since vaccination, which differed between the two groups (Table 1). Thus, the results of the immunological assays were adjusted by the time (in days) between full vaccine administration and blood collection for the study using linear regression.

\section{Materials and methods}

\section{Ethics, consent, and permission}

Thirty-three subjects who received either mRNA vaccines $(n=16)$ or the adenoviral vector vaccine Ad26.COV2.S $(n=17)$ were enrolled on August 9-10, 2021, at the Rutgers Robert Wood Johnson Medical School, New Brunswick, NJ, USA. All participants selfreported no history of SARS-CoV-2 infection and date of vaccination and consented to blood draws as well as collection of demographic data. All study activities were approved by the Rutgers Institutional Review Board (Pro2020000655).

\section{Biosafety protocols}

All work involving blood products from SARS-CoV-2infected subjects was performed in a biosafety level $2+$ (BSL-2+) laboratory-utilizing protocols approved by the Rutgers Institutional Biosafety Committee. All plasma samples were heat-inactivated at $56^{\circ} \mathrm{C}$ for $60 \mathrm{~min}$ before testing. Work involving live SARS-CoV-2 was performed

Table 1 Demographics and clinical information of study participants, stratified by vaccine type

\begin{tabular}{|c|c|c|c|c|}
\hline & Overall* $(n=33)$ & $\mathrm{J} \& \mathrm{~J}(n=17)$ & mRNA $(n=16)$ & $p$ \\
\hline Age (years) & $49.8 \pm 15.6$ & $52.3 \pm 13.3$ & $47.3 \pm 17.7$ & 0.066 \\
\hline \multicolumn{5}{|l|}{ Gender } \\
\hline Female & 17/33 (51\%) & $8 / 17(47 \%)$ & $9 / 16(56 \%)$ & \multirow[t]{2}{*}{0.279} \\
\hline Male & $16 / 33(49 \%)$ & 9/17 (53\%) & $7 / 16(44 \%)$ & \\
\hline BMI $\left(\mathrm{kg} / \mathrm{m}^{2}\right)$ & $26.7 \pm 5.3$ & $27.4 \pm 5.2$ & $25.9 \pm 5.4$ & 0.413 \\
\hline \multicolumn{5}{|l|}{ Race/ethnicity } \\
\hline Asian & 10/33 (30\%) & $4 / 17(24 \%)$ & $6 / 16(38 \%)$ & \multirow[t]{3}{*}{0.350} \\
\hline Others & 1/33 (3\%) & 0/17 (0\%) & $1 / 16(6 \%)$ & \\
\hline White & $22 / 33(67 \%)$ & 13/17 (76\%) & $9 / 16(56 \%)$ & \\
\hline Hispanic or Latinx & 0/33 (0\%) & $0 / 17(0 \%)$ & 0/16 (0\%) & - \\
\hline \multicolumn{5}{|l|}{ Comorbidities } \\
\hline Yes & 10/33 (30\%) & $5^{* *} / 17(29 \%)$ & $5^{* *} / 16(31 \%)$ & \multirow[t]{2}{*}{0.909} \\
\hline No & $23 / 33(70 \%)$ & $12 / 17(71 \%)$ & $11 / 16(69 \%)$ & \\
\hline \multicolumn{5}{|l|}{ Immunodeficiencies } \\
\hline Yes & 3/33 (9\%) & 0/17 (0\%) & $3^{* * *} / 16(19 \%)$ & \multirow[t]{2}{*}{0.061} \\
\hline No & 30/33 (91\%) & $17 / 17$ (100\%) & 13/16 (81\%) & \\
\hline Days since vaccination & $168.2 \pm 57.9$ & $189.7 \pm 62.8$ & $145.2 \pm 43.3$ & 0.025 \\
\hline
\end{tabular}

Data are presented as mean \pm standard deviation or proportion $(n / N(\%))$

$B M I$ body mass index

*All study subjects were fully vaccinated [one-dose Johnson \& Johnson (J\&) or two-dose mRNA vaccines]

**Hypertension $(n=6)$, obesity $(n=3)$, diabetes $(n=2)$, asthma $(n=2)$, and coronary artery disease $(n=1)$ (some conditions were concurrent)

***Neutropenia $(n=1)$, rheumatoid arthritis $(n=1)$, and use of corticosteroids $(n=1)$ 
in a biosafety level 3 (BSL-3) laboratory-utilizing protocols approved by the Rutgers Institutional Biosafety Committee.

\section{Antibody binding by enzyme-linked immunosorbent assay (ELISA)}

Antibody binding was performed by ELISA platform utilizing SARS-CoV-2 receptor-binding domain (RBD) of the Spike protein as solid-phase antigen and standard operating procedures, as described [7]. Each sample was tested in duplicate. End-point titers were calculated using an established cutoff [7] and backgroundsubtracted data.

\section{Cell lines}

Vero E6 were obtained from the American Type Culture Collection (ATCC), Manassas, USA; HeLa cells stably expressing ACE2 (HeLa-ACE2) were obtained from Dennis Burton at the Scripps Research Institute [8]. All cell lines were maintained in high-glucose Dulbecco's modified Eagle's medium (DMEM; Corning, Manassas, USA) supplemented with $10 \%$ fetal bovine serum (FBS; Seradigm, Radnor, USA), $2 \mathrm{mM}$ L-glutamine, and $1 \%$ penicillin/streptomycin (Corning, Manassas, USA) and incubated in humidified atmospheric air containing 5\% $\mathrm{CO}_{2}$ at $37^{\circ} \mathrm{C}$.

\section{SARS-CoV-2 virus}

The virus stock of mNeonGreen (mNG) SARS-CoV-2 was obtained from Pei-Yong Shi at the University of Texas Medical Branch at Galveston. The virus stock was produced using the virus isolate of the first patient diagnosed in the USA, in which the ORF7 of the viral genome was replaced with the reported mNG gene [9]. Propagation of viral stocks was performed with Vero E6 cells using $2 \%$ FBS. The virus titers were determined by standard plaque assay utilizing Vero E6 cells [10] and recorded as plaque-forming units per milliliter $(\mathrm{PFU} / \mathrm{mL})$.

\section{SARS-CoV-2 neutralization assay}

HeLa-Ace2 cells were seeded in 96-well black opticalbottom plates at a density of $1 \times 10^{4}$ cells/well in FluoroBrite DMEM (Thermo Fisher Scientific, Waltham, USA) containing 4\% FBS (Seradigm), $2 \mathrm{mM}$ L-glutamine, and $1 \%$ penicillin/streptomycin (Corning, Manassas, USA), and incubated overnight at $37{ }^{\circ} \mathrm{C}$ with $5 \% \mathrm{CO}_{2}$. On the following day, each sample was subjected to two-fold serial dilution in DMEM without FBS and incubated with mNG SARS-CoV-2 at $37{ }^{\circ} \mathrm{C}$ for $1.5 \mathrm{~h}$. The virusplasma mixture was transferred to 96 -well plates containing Hela-Ace 2 cells at a final multiplicity of infection (MOI) of 0.25 (viral PFU:cell). For each sample, the starting dilution was $1: 20$ and the final dilution of 1 : 10,240. After incubating infected cells at $37^{\circ} \mathrm{C}$ for $20 \mathrm{~h}$,
mNG SARS-CoV-2 fluorescence was measured using a Cytation $^{\text {tw }} 5$ reader (BioTek, Winooski, USA). Each sample was tested in duplicate. Relative fluorescent units were converted to percent neutralization by normalizing the sample treatment to non-sample treatment controls and plotting the data with a nonlinear regression curve fit to determine the titer neutralizing $50 \%$ of SARS-CoV2 fluorescence $\left(\mathrm{NT}_{50}\right)$.

\section{PBMC isolation and storage}

Peripheral blood mononuclear cells (PBMC) were isolated by Ficoll density gradient centrifugation (FicollPaque, GE Healthcare, Uppsala, Sweden), as described [11], cryopreserved in liquid nitrogen in FBS containing 10\% dimethyl sulfoxide (DMSO; Thermo Fischer Scientific, Waltham, MA, USA), and stored until use.

\section{RBD-specific $B$ cell immunostaining}

To form RBD tetramers, biotinylated RBD (BioLegend, San Diego, CA, USA) was mixed in separate tubes with streptavidin-conjugated with Alexa Fluor 647 or BV421 (BD Biosciences, San Jose, CA, USA) at a 4:1 molar ratio for $1 \mathrm{~h}$ at $4{ }^{\circ} \mathrm{C}$. PBMCs were stained with fixable viability stain 780 (BD Biosciences, Franklin Lakes, USA), incubated for 10 min with human Fc receptor blocking reagent (BD Biosciences, Franklin Lakes, NJ, USA), and then stained with the two fluorescent RBD tetramers, antibodies to CD19-BV700 (HIB19, Bio Legend, San Diego, CA, USA) and CD20-PE-CF594 (2H7, BD Biosciences, San Jose, CA, USA) to detect RBD-specific B cells, and APC-Cy7-labeled antibodies against CD3 (UCHT1), CD4 (OKT4), CD14 (C1D3), and CD16 (CD16) (all from Thermo Fisher Scientific, Waltham, MA, USA) to eliminate non-B cells. Samples were incubated for $30 \mathrm{~min}$ on ice in the dark to allow for antibody binding, washed twice with FACS buffer (2\% FBS in PBS), fixed for 20 min with 4 percent paraformaldehyde (PFA; Thermo Fisher Scientific, Waltham, MA, USA), and stored at 4 ${ }^{\circ} \mathrm{C}$ overnight. At least 500,000 events were collected per sample utilizing a Fortessa X-20 flow cytometer (BD Biosciences, San Jose, CA, USA). After removing dead and non-B cells, B cells were separated as $\mathrm{CD} 19^{+} \mathrm{CD} 20^{+}$, and the frequency of $B$ cells positive for both RBD tetramers was determined by using the Flow Jo software (Flow Jo LLC, USA).

\section{SARS-CoV-2-derived peptides}

A megapool (MP_S) of 253 15-mer synthetic peptides overlapping by 10-residues that cover the entire spike (S) antigen was generated based on predicted SARS-CoV-2 CD4 $\mathrm{T}$ cell epitopes, as previously reported $[12,13]$. 


\section{IFN $\gamma$ release assay}

PBMC were washed in pre-warmed RPMI 1640 supplemented with $2 \mathrm{mM}$ L-glutamine, 10\% FBS, $100 \mathrm{U} / \mathrm{ml}$ penicillin, and $100 \mu \mathrm{g} / \mathrm{ml}$ streptomycin (complete RPMI) (all from Corning cellgro, Manassas, VA, USA), seeded in a 48-well cell culture plate at a density of $1 \times 10^{4}$ cells/well in complete RPMI, and stimulated with $1 \mu \mathrm{g} /$ $\mathrm{ml}$ of the SARS-CoV-2 MP_S peptide pool or $0.1 \%$ DMSO (vehicle control). Cell culture plates were incubated for $24 \mathrm{~h}$ at $37{ }^{\circ} \mathrm{C}$ in a $5 \% \mathrm{CO}_{2}$-humidified atmosphere. Each sample was tested in duplicate. As a positive control, two wells per sample were treated with a mixture of $25 \mathrm{ng} / \mathrm{ml}$ phorbol 12-myristate 13-acetate (PMA) (Sigma-Aldrich, St. Louis, MO, USA) and $0.5 \mu \mathrm{M}$ ionomycin calcium salt (Enzo Life Sciences, Farmingdale, CT, USA) for $2 \mathrm{~h}$. Supernatants were collected, and levels of IFN $\gamma$ in supernatants were assayed using a commercial Human IFNY ELISA kit (BD Biosciences, San Jose, $\mathrm{CA}$ ), according to the manufacturer's instructions.

\section{Statistical analysis}

Baseline demographic and other variables were tested using a two-sample proportion test and Student's $t$-test. All flow cytometry data were analyzed with the FlowJo v12 software (FlowJo LLC, Ashland, OR, USA). Measurements from all immunological assays were compared between the two study groups using the MannWhitney $U$ test. Linear regression was performed to assess the dependency of immunological measurements on the type of vaccination while adjusting for time (days) elapsed since vaccination and adjusting for age. The correlation was analyzed using Spearman's rank correlation. For all tests, $p<0.05$ was considered significant. Statistical analyses were performed with Stata (version 17, StataCorp LLC, College Station, USA) and GraphPad Prism version 8.4 (Graph Pad Software Inc., La Jolla, USA).

\section{Antibody binding and neutralization}

All vaccines express the full-length SARS-CoV-2 Spike protein [2-4]. We analyzed the plasma of all subjects for IgG antibody binding the receptor-binding domain (RBD) of the S1 subunit of the SARS-CoV-2 Spike protein and for neutralizing antibodies. We chose RBD as the target antigen of the antibody response, because the neutralizing activity of plasma is largely directed against RBD, as shown by us and others [14-16]. The virus neutralization activity of plasma was measured with an assay utilizing replication-competent SARS-CoV-2 virus. We found that both $\mathrm{Ab}$ binding and neutralizing titers were higher in the mRNA-vaccinated group relative to adenoviral vector vaccinees (Fig. $1 \mathrm{AB}$ ). The differences between the groups were statistically significant after adjusting for days since vaccination (Table 2).

\section{$R B D+B$ cell frequencies}

The levels of specific antibodies in the circulation physiologically decrease with time elapsed since exposure to antigen $[14,17,18]$. Thus, assessing the durability of vaccine-induced responses and protection from occurrence and clinical severity of breakthrough infection requires the evaluation of antigen-specific $B$ cells and $T$ cells. To analyze the memory $\mathrm{B}$ cell response elicited by the vaccine, we enumerated RBD-specific $B$ cells (RBDtetramer-positive $\mathrm{CD} 19^{+} \mathrm{CD} 20^{+}$) utilizing dual $\mathrm{RBD}$ tetramer staining for high specificity and multi-color flow cytometry (the gating strategy is shown in Additional file 1: Fig. S1). We found that the differences in RBD-specific B cell frequencies between the mRNAand adenoviral vector-vaccinated subjects were not statistically significant (Fig. 1C and Table 2).

\section{Interferon gamma (IFNY) release assay}

A straightforward method to assess antigen-specific $\mathrm{T}$ cells is measuring the production of $\mathrm{T}$ cell cytokines, such as IFNy, by peripheral blood mononuclear cells (PBMC) stimulated ex vivo with peptides representing $\mathrm{T}$ cell epitopes, as performed for many infectious and noninfectious conditions (for example, [19]). We used a previously described peptide pool containing hundreds of overlapping 15-meric peptides spanning the Spike protein (MP_S) [12] for PBMC stimulation and detection of IFNY release by ELISA. This assay showed no significant differences between the two groups of vaccinees (Fig. 1D and Table 2).

\section{Correlation between humoral and cellular responses}

To assess the complementarity between humoral and cellular responses, we calculated the correlations among the results of each immunological assay in a pairwise manner. As expected, anti-RBD antibody-binding and plasma-neutralizing activity highly correlated with each other (corr $=0.87$-where 1 is the maximum possible value), since the neutralizing activity of the plasma mostly resides in the RBD-specific antibodies, as noted above. In contrast, the correlation between cellular and humoral assay and between the two cellular assays with each other was very low (corr $<0.15$ ), indicating that these immunological readouts are independent of each other.

\section{Effect of age on the vaccine response}

Since the two vaccine groups showed a non-significant trend for age mean $(p=0.06)$ (Table 1$)$ and age may affect the response to SARS-CoV-2 vaccination [20], we calculated the correlations between age and either antibody responses or cellular responses. We found a weakmoderate correlation between the age and antibody response [Age and IgG (corr $=-0.25, p=0.16$ ); age and 
A
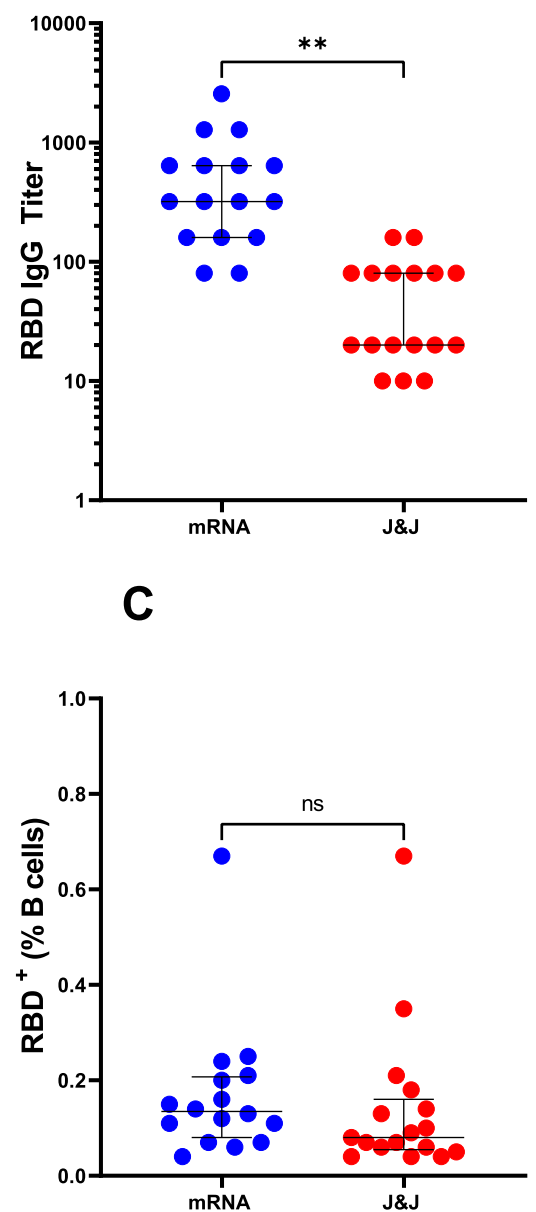

B

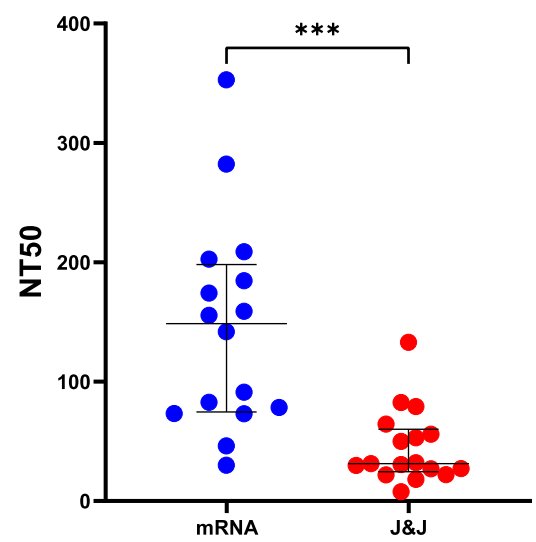

D

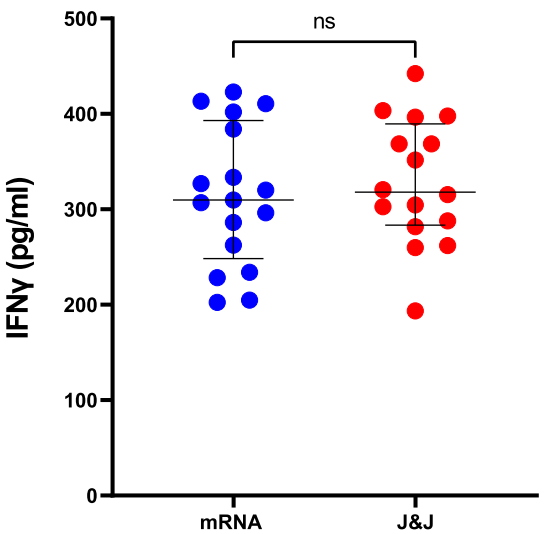

Fig. 1 Humoral and cellular responses elicited by mRNA and adenoviral vector-based COVID-19 vaccines. Each circle indicates one subject. Blue circles represent subjects who received two doses of mRNA vaccine $(n=16)$, and red circles represent subjects who received the adenoviral vector-based (J\&) vaccine $(n=17)$. The dot plots show $\mathbf{A}$ anti-RBD IgG antibody levels, B neutralizing titers expressed as NT50 (reciprocal dilution of plasma yielding 50\% neutralization of live SARS-CoV-2 virus), and $\mathbf{C}$ frequency (\%) of RBD-specific B cells. B cells $\left(C D 19^{+}\right.$CD20 $\left.0^{+}\right)$were analyzed for RBD specificity utilizing dual fluorescent labeling of RBD tetramers. D IFNy (pg/ml) production by antigen-specific T cells. PBMCs from each subject were stimulated with a megapool of overlapping synthetic peptides (15-mers) covering the entire Spike (S) antigen. Supernatants were collected after $24 \mathrm{~h}$ of stimulation. In all panels, the solid black lines represent the median and interquartile range. Statistical analyses were conducted by the Mann-Whitney $U$ test for unpaired samples (** $p \leq 0.01 ;{ }^{* *} p \leq 0.001$; ns, non-significant, $p>0.05$ )

Table 2 Estimates of the mean difference in each measurement between mRNA and J\& (reference) vaccinees from a linear regression, adjusted for time since vaccination

\begin{tabular}{llll}
\hline Variable & Estimate $(\mathbf{9 5 \%} \mathrm{Cl})$ & Standard error & $\boldsymbol{p}$ \\
\hline Anti-RBD IgG titers & $519.9(169.1,870.8)$ & 171.8 & 0.0051 \\
NT50 & $99.1(47.9,150.3)$ & 25.1 & 0.0004 \\
RBD $^{+}(\% B$ cells $)$ & $0.036(-0.084,0.156)$ & 0.059 & 0.55 \\
IFN $\boldsymbol{Y}(\mathbf{p g} / \mathbf{m l})$ & $35.7(-15.0,86.4)$ & 24.8 & 0.16 \\
\hline
\end{tabular}

Cl confidence interval, $R B D$ receptor-binding domain, IgG immunoglobulin $\mathrm{G}$, NT50 neutralization titer at $50 \%$ inhibition neutralizing antibodies (corr $=-0.23, p=0.20)]$ and a very weak correlation between age and cellular response [age and B cells (corr $=0.002, p=0.99$ ); age and T cells (corr $=-0.09, p=0.60)$. To assess whether age is an explanation for the differences in antibody response between the vaccine groups, we adjusted for age in a linear regression model. The resulting adjusted difference in means was $-477.7(p=0.01)$ for anti-RBD IgG and $94.2(p<0.001)$ for neutralizing antibodies. Thus, our conclusions did not change when we controlled for age.

In conclusion, mRNA vaccination results in higher levels of circulating binding and neutralizing antibodies than the adenoviral vector counterpart (at least in the timeframe of our study, i.e., 5 months after vaccination 
on average), while the antigen-specific cellular responses to the two vaccine classes show no significant differences. It is noted that a limitation of our study is the small sample size ( $n=33$ in the two groups). The different antibody levels are likely due to the single-dose administration of the adenoviral vector-based vaccine vs the two-dose protocols applied with the mRNA vaccines. Indeed, antibody titers measured after the second dose of mRNA vaccines are higher than after the first dose [5, 21 , and the antibody responses to a booster dose are more vigorous than those elicited by primary vaccination protocols [22, 23]. Thus, circulating antibody levels increase with the number of doses of our current SARS$\mathrm{CoV}-2$ vaccines. Since vaccine-induced neutralizing antibodies are highly correlated with immune protection from symptomatic infection $[24,25]$ - a correlation supported by murine studies [26], our data imply that a booster dose of the Ad26.COV2.S is particularly advisable, especially in the face of the global rise of COVID19 morbidity due to the highly infectious SARS-CoV-2 Delta variant [1]. Indeed, the administration of a second vaccine dose of Ad26.COV2.S predictably induces a stronger antibody response than the primary vaccination, as per interim data by the manufacturer [27].

Our results may indirectly help explain why protection from symptomatic infection afforded by SARS-CoV-2 vaccination tends to wane while vaccine efficacy in preventing hospitalization and death persists $[28,29]$. The observed dichotomy between humoral and cellular immune responses elicited by the two SARS-CoV-2 vaccine classes is consistent with different trajectories of decay of the humoral and cellular responses, with circulating antibody levels decreasing more rapidly than antigenspecific memory responses, which tend to last longer. One may postulate that humoral immunity provides a "ready-to-go" response to reinfection that limits viral replication and the consequent development of symptoms. In contrast, memory immune responses, which require longer to express protective functions even in vaccinated individuals, may defend against severe disease and hospitalization. If so, rapidly decaying humoral responses vis-à-vis persisting cellular responses to vaccination might underlie the loss of protection from symptomatic infection while defense from severe consequences of infection, such as hospitalization and death, is still afforded. Future studies on the durability of vaccine-induced protection, the protective effects of booster doses, and the underlying immunological mechanisms will test our proposition.

\section{Abbreviations}

ACE2: Angiotensin-converting enzyme-2; Ad26.COV2.S: Johnson and Johnson-Janssen adenoviral vector; ATCC: American Type Culture Collection Center; BNT162b2: BioNTech-Pfizer mRNA vaccine; BSL-2+: Biosafety level 2+; BSL-3: Biosafety level 3; DMEM: High-glucose Dulbecco's modified Eagle's medium; DMSO: Dimethyl sulfoxide; ELISA: Enzyme-linked immunosorbent assay; FBS: Fetal bovine serum; HeLa-ACE2: HeLa cells stably expressing ACE2; IFNy: Interferon gamma; mNG: mNeonGreen; MOI: Multiplicity of infection; MP_S: Overlapping 15-meric peptides spanning the spike protein; mRNA1273: Moderna mRNA vaccine; NT50: Titer neutralizing 50\% of SARS-CoV-2 fluorescence; PBMC: Peripheral blood mononuclear cells;

PFA: Paraformaldehyde; PFU/ml: Plaque forming units per milliliter; PMA: Phorbol 12-myristate 13-acetate; RBD: Receptor-binding domain; RBDspecific B cells: RBD-tetramer-positive $\mathrm{CD}_{19}{ }^{+} \mathrm{CD} 2 \mathrm{O}^{+}$; S: Spike protein; SARSCoV-2: Severe acute respiratory syndrome coronavirus-2

\section{Supplementary Information}

The online version contains supplementary material available at https://doi. org/10.1186/s12916-022-02252-0.

Additional file 1: Figure S1. Gating strategy for SARS-CoV-2 S1 RBDspecific memory B cells. (A) Physical parameters; (B) Exclusion of dead cells and non-B cells $\left(\mathrm{CD} 14^{+}, \mathrm{CD}^{+}, \mathrm{CD}^{+}, \mathrm{CD} 16^{+}\right) ;(\mathbf{C}) \mathrm{CD}_{1}{ }^{+} \mathrm{CD} 20^{+} \mathrm{B}$ cells were further gated to distinguish (D) RBD-specific $B$ cells based on dual labeling in the same staining tube with two fluorescent RBD tetramers separately conjugated with Alexa Fluor 647 and BV421.

\section{Acknowledgements}

We thank the 33 study participants that prompted this study, Dennis Burton and Pei-Yong Shi for providing biological reagents, David Alland for helping obtain live SARS-CoV-2 virus, and Martin Blaser and Karl Drlica for the critical reading of the manuscript.

\section{Authors' contributions}

R.U., N.B., H.M., and P.K.M. contributed equally to this work. R.U., D.M., F.C., and A.O. were responsible for obtaining the patient samples. R.U., N.B., H.M., P.K.M., J.R., S.G., and M.L.G. conceived the research design, analyzed the data, and interpreted the results. R.U., N.B., H.M., P.K.M., D.M., F.C., and A.O.

collected the data. A.P., D.W., and A.S. contributed vital new reagents. R.U., N.B., J.R., S.G., and M.L.G. wrote the manuscript. R.U., J.R., and M.L.G. revised the manuscripts. All authors read and approved the final manuscript.

\section{Funding}

This work was funded by NIH grants R01 HL149450, R01 HL149450-S1, R61 HD105619, R01 Al158911, U01 Al122285-S1, UL1 TR003017, and NIH contract 75N9301900065

Availability of data and materials

Data are available on reasonable request to the corresponding author due to privacy/ethical restrictions

\section{Declarations}

Ethics approval and consent to participate

The ethics approval was obtained from the Rutgers Institutional Review Board (Pro2020000655). Informed written consent was obtained from each participant before enrollment.

\section{Consent for publication}

Consent to publish has been obtained from all the subjects in the study.

\section{Competing interests}

Rutgers University has filed for patent protection for various aspects of antiSARS-CoV-2 antibody detection and its uses. La Jolla Institute has filed for patent protection for various aspects of T cell epitope and vaccine design work. M.L.G. is a consultant for Biomerieux. A.S. is a consultant for Gritstone, Flow Pharma, Arcturus, Immunoscape, CellCarta, Oxford Immunotec, and Avalia.

\section{Author details}

${ }^{1}$ Public Health Research Institute, Rutgers New Jersey Medical School, ICPH Building, W250Q, 225 Warren Street, Newark, NJ 07103, USA. ²Department of Medicine, Rutgers New Jersey Medical School, ICPH building, W250Q, 225 Warren Street, Newark, NJ 07103, USA. ${ }^{3}$ Clinical Research Center, Rutgers Robert Wood Johnson Medical School, New Brunswick, NJ, USA. ${ }^{4}$ Global 
Tuberculosis Institute, Rutgers New Jersey Medical School, ICPH building, W250Q, 225 Warren Street, Newark, NJ 07103, USA. ${ }^{5}$ Center for Infectious Disease and Vaccine Research, La Jolla Institute for Immunology, La Jolla, CA, USA. ${ }^{6}$ Department of Medicine, Division of Infectious Diseases and Global Public Health, University of California, San Diego, La Jolla, CA, USA. 7Department of Biostatistics and Epidemiology, School of Public Health, Rutgers University, Piscataway, NJ, USA. ${ }^{8}$ Department of Pediatrics, Rutgers Robert Wood Johnson Medical School, New Brunswick, NJ, USA.

Received: 12 October 2021 Accepted: 11 January 2022

Published online: 25 January 2022

\section{References}

1. Luo CH, Morris CP, Sachithanandham J, Amadi A, Gaston D, Li M, et al. Infection with the SARS-CoV-2 delta variant is associated with higher infectious virus loads compared to the alpha variant in both unvaccinated and vaccinated individuals. medRxiv. 2021;2021(21262077):08-15.

2. Polack FP, Thomas SJ, Kitchin N, Absalon J, Gurtman A, Lockhart S, et al. Safety and efficacy of the BNT162b2 mRNA COVID-19 vaccine. N Engl J Med. 2020;383(27):2603-15. https://doi.org/10.1056/NEJMoa2034577.

3. Baden LR, El Sahly HM, Essink B, Kotloff K, Frey S, Novak R, et al. Efficacy and safety of the mRNA-1273 SARS-CoV-2 vaccine. N Engl J Med. 2021;384(5): 403-16. https://doi.org/10.1056/NEJMoa2035389.

4. Sadoff J, Le Gars M, Shukarev G, Heerwegh D, Truyers C, de Groot AM, et al. Interim results of a phase 1-2a trial of Ad26.COV2.S COVID-19 vaccine. N Engl J Med. 2021;384(19):1824-35. https://doi.org/10.1056/NEJMoa2034201.

5. Walsh EE, Frenck RW Jr, Falsey AR, Kitchin N, Absalon J, Gurtman A, et al. Safety and immunogenicity of two RNA-based COVID-19 vaccine candidates. N Engl J Med. 2020;383(25):2439-50. https://doi.org/10.1056/ NEJMoa2027906.

6. Tada T, Zhou H, Samanovic MI, Dcosta BM, Cornelius A, Mulligan MJ, et al. Comparison of neutralizing antibody titers elicited by mRNA and adenoviral vector vaccine against SARS-CoV-2 variants. bioRxiv. 2021;2021(452771):0719.

7. Datta P, Ukey R, Bruiners N, Honnen W, Carayannopoulos MO, Reichman C, et al. Highly versatile antibody binding assay for the detection of SARS-CoV2 infection. medRxiv. 2021;2021 (21260266):07-9.

8. Rogers TF, Zhao F, Huang D, Beutler N, Burns A, He WT, et al. Isolation of potent SARS-CoV-2 neutralizing antibodies and protection from disease in a small animal model. Science. 2020;369(6506):956-63. https://doi.org/10.112 6/science.abc7520.

9. Xie X, Muruato A, Lokugamage KG, Narayanan K, Zhang X, Zou J, et al. An infectious cDNA clone of SARS-CoV-2. Cell Host Microbe. 2020;27(5):841-8 e3.

10. Case JB, Bailey AL, Kim AS, Chen RE, Diamond MS. Growth, detection, quantification, and inactivation of SARS-CoV-2. Virology. 2020;548:39-48. https://doi.org/10.1016/j.virol.2020.05.015.

11. Arrigucci R, Bushkin Y, Radford F, Lakehal K, Vir P, Pine R, et al. FISH-Flow, a protocol for the concurrent detection of mRNA and protein in single cells using fluorescence in situ hybridization and flow cytometry. Nat Protoc. 2017;12(6):1245-60. https://doi.org/10.1038/nprot.2017.039.

12. Grifoni A, Sidney J, Zhang Y, Scheuermann RH, Peters B, Sette A. A sequence homology and bioinformatic approach can predict candidate targets for immune responses to SARS-CoV-2. Cell Host Microbe. 2020;27(4): $671-80 \mathrm{e} 2$.

13. Grifoni A, Weiskopf D, Ramirez SI, Mateus J, Dan JM, Moderbacher CR, et al. Targets of T cell responses to SARS-CoV-2 coronavirus in humans with COVID-19 disease and unexposed individuals. Cell. 2020;181(7):1489-501 e15.

14. Mishra PK, Bruiners N, Ukey R, Datta P, Onyuka A, Handler D, et al. Vaccination boosts protective responses and counters SARS-CoV-2-induced pathogenic memory B cells. medRxiv. 2021;2021(21255153):04-11.

15. Greaney AJ, Loes AN, Crawford KHD, Starr TN, Malone KD, Chu HY, et al. Comprehensive mapping of mutations in the SARS-CoV-2 receptor-binding domain that affect recognition by polyclonal human plasma antibodies. Cell Host Microbe. 2021;29(3):463-76 e6.

16. Stamatatos L, Czartoski J, Wan YH, Homad L, Rubin V, Glantz H, et al. mRNA vaccination boosts cross-variant neutralizing antibodies elicited by SARSCoV-2 infection. Science. 2021;372(6549):1413-8. https://doi.org/10.1126/ science.abg9175.
17. Ibarrondo FJ, Fulcher JA, Goodman-Meza D, Elliott J, Hofmann C, Hausner MA, et al. Rapid decay of anti-SARS-CoV-2 antibodies in persons with mild COVID-19. N Engl J Med. 2020;383(11):1085-7. https://doi.org/10.1056/ NEJMc2025179.

18. Tea F, Ospina Stella A, Aggarwal A, Ross Darley D, Pilli D, Vitale D, et al. SARS-CoV-2 neutralizing antibodies: longevity, breadth, and evasion by emerging viral variants. PLoS Med. 2021;18(7):e1003656. https://doi.org/1 0.1371/journal.pmed.1003656.

19. Lindestam Arlehamn CS, McKinney DM, Carpenter C, Paul S, Rozot V, Makgotlho $E$, et al. A quantitative analysis of complexity of human pathogen-specific CD4 T cell responses in healthy M. tuberculosis infected South Africans. PLoS Pathog. 2016;12(7):e1005760.

20. Collier DA, Ferreira I, Kotagiri P, Datir RP, Lim EY, Touizer E, et al. Age-related immune response heterogeneity to SARS-CoV-2 vaccine BNT162b2. Nature. 2021;596(7872):417-22. https://doi.org/10.1038/s41586-021-03739-1.

21. Favresse J, Bayart JL, Mullier F, Dogné JM, Closset M, Douxfils J. Early antibody response in health-care professionals after two doses of SARS-CoV2 mRNA vaccine (BNT162b2). Clin Microbiol Infect. 2021;27(9) 1351:e5-7.

22. Choi A, Koch M, Wu K, Chu L, Ma L, Hill A, et al. Safety and immunogenicity of SARS-CoV-2 variant mRNA vaccine boosters in healthy adults: an interim analysis. Nat Med. 2021;27(11):2025-31. https://doi.org/10.1038/s41591-02101527-y.

23. Demonbreun AR, Sancilio A, Vaught LA, Reiser NL, Pesce L, McNally EM, et al. Antibody titers before and after booster doses of SARS-CoV-2 mRNA vaccines in healthy adults. medRxiv. 2021;2021(21266555):11-9.

24. Khoury DS, Cromer D, Reynaldi A, Schlub TE, Wheatley AK, Juno JA, et al. Neutralizing antibody levels are highly predictive of immune protection from symptomatic SARS-CoV-2 infection. Nat Med. 2021;27(7):1205-11. https://doi.org/10.1038/s41591-021-01377-8.

25. Earle KA, Ambrosino DM, Fiore-Gartland A, Goldblatt D, Gilbert PB, Siber GR, et al. Evidence for antibody as a protective correlate for COVID-19 vaccines. Vaccine. 2021;39(32):4423-8. https://doi.org/10.1016/j.vaccine.2021.05.063.

26. Israelow B, Mao T, Klein J, Song E, Menasche B, Omer SB, et al. Adaptive immune determinants of viral clearance and protection in mouse models of SARS-CoV-2. bioRxiv. 2021;2021(444825): 05-19.

27. Sadoff J, Le Gars M, Cardenas V, Shukarev G, Vaissiere N, Heerwegh D, et al. Durability of antibody responses elicited by a single dose of Ad26.COV2.S and substantial increase following late boosting. medRxiv. 2021; 2021(21262569):08-25

28. Chemaitelly H, Tang P, Hasan MR, AlMukdad S, Yassine HM, Benslimane FM, et al. Waning of BNT162b2 vaccine protection against SARS-CoV-2 infection in Qatar. medRxiv. 2021;2021(21262584):08-25.

29. Tartof SY, Slezak JM, Fischer H, Hong V, Ackerson BK, Ranasinghe ON, et al. Effectiveness of mRNA BNT162b2 COVID-19 vaccine up to 6 months in a large integrated health system in the USA: a retrospective cohort study. Lancet. 2021;398(10309):1407-16. https://doi.org/10.1016/S0140-6736(21)021 83-8.

\section{Publisher's Note}

Springer Nature remains neutral with regard to jurisdictional claims in published maps and institutional affiliations.

Ready to submit your research? Choose BMC and benefit from:

- fast, convenient online submission

- thorough peer review by experienced researchers in your field

- rapid publication on acceptance

- support for research data, including large and complex data types

- gold Open Access which fosters wider collaboration and increased citations

- maximum visibility for your research: over $100 \mathrm{M}$ website views per year

At BMC, research is always in progress.

Learn more biomedcentral.com/submissions 